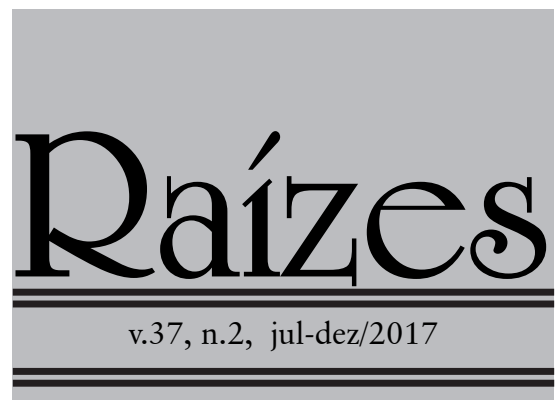

\title{
MOTIVAÇÃO DE JOVENS PARA O TRABALHO NA AMAZÔNIA PARAENSE
}

\author{
Myrla Franco Antunes Resque, Dalva Maria da Mota
}

RESUMO

A literatura, ao tratar da motivação de jovens filhos de agricultores para o trabalho no espaço rural, mostra dilemas entre "sair e ficar" no estabelecimento familiar. Contrariamente, os nossos primeiros contatos no campo indicaram apenas o desejo de permanência. Motivadas por esse contraste, investigamos a questão e, neste artigo, analisamos a motivação de jovens para trabalhar na sua região de origem. Amparada na sociologia rural e do trabalho, a pesquisa foi realizada por meio de um estudo de caso na localidade de Perseverança, São Domingos do Capim (PA). Observações e entrevistas com jovens e seus pais constaram nos procedimentos de pesquisa. Concluímos que, em sua maioria, os jovens têm interesse em continuar vivendo e trabalhando na localidade, mas o desejo de autonomia pessoal e financeira motiva-os a buscar uma formação profissional para conquistar um trabalho assalariado ou mais remunerado perto de casa ou no seu próprio estabelecimento. Há variação de motivações para o trabalho segundo o recorte de gênero, mas a condição de precariedade alcança todos os jovens entrevistados. Palavras-chave: Juventude; Nordeste Paraense; Motivações; Assalariamento; Trabalho Familiar.

\section{YOUNG PEOPLE’S MOTIVATION TO WORK IN THE PARÁ STATE AMAZON}

\section{ABSTRACT}

In what concerns the motivation for farmers'young children to work in the rural area, literature shows a dilemma between "stay and go" in the family establishment. On the contrary, our first contacts in the field showed they will to stay. Motivated by the contrast, we investigated the issue and our objective in this article is to analyze the motivation for young people to work in their region of origin. Supported by the rural and work sociology, the research was fulfilled through a case study in the locality of Perseverança, São Domingos do Capim (PA). Observations and interviews with youngsters and their parents were part of the procedure of research. We concluded that, in their majority, the young people have an interest in continuing living and working in the locality, but the aspiration for personal and financial autonomy motivate them to look for professional education in order to acquire a paid job near at home or in their own establishment. There are variations in the motivation to work according to the gender cut, but the condition of precariousness reaches all the young individuals interviewed.

Keywords: Youth; Paraense Northeast; Motivations; Family work.

Mestre em Agricultura Familiar e Desenvolvimento Sustentável pela Universidade Federal do Pará, em Belém (PA). E-mail: myrlantunes@gmail.com.

Doutora em Sociologia, pesquisadora da Embrapa Amazônia Oriental, em Belém (PA), bolsista de produtividade do CNPq. E-mail: dalva.mota@embrapa.br. 


\section{INTRODUÇÃO}

Estudos sobre a juventude rural são historicamente recentes. Segundo Marin e Andreu (2009), a academia voltou-se para a juventude rural somente nas últimas décadas do século XIX, no âmbito dos estudos sobre a industrialização tardia dos países latino-americanos e a correspondente modernização da sua agricultura. Para os autores, a ideia de juventude rural foi inserida nos discursos e nas práticas das instituições desenvolvimentistas na Europa Ocidental e nos Estados Unidos e também no contexto de internacionalização da modernização da agricultura na América Latina após a Segunda Guerra Mundial.

$\mathrm{Na}$ América Latina, os estudos sobre os jovens nos espaços rurais são recentes, se comparados aos que privilegiam o homem adulto e agricultor. Estudiosos consideraram a diversidade de atores e as especificidades do rural, para além da agricultura, somente a partir da década de 90 do século XX. Mesmo assim, persistiam insuficiências quanto à conceituação da juventude rural e ao estabelecimento de um quadro teórico, conforme analisado por Durston (1998), um dos precursores dos estudos sobre a juventude no espaço rural latino-americano. Insistiu o autor em diferentes abordagens que privilegiavam o dimensionamento do significado de juventude, o momento em que se encontra o jovem, considerando não apenas sua idade cronológica, mas também a etapa de sua vida. A perspectiva do autor é compartilhada no Brasil por Carneiro (2007), Weisheimer (2007) e Stropasolas (2006) que analisam a juventude de forma heterogênea no seu universo plural, atribuindo importância à especificidade dos contextos sociais, econômicos, culturais em que vivem os jovens.

No que diz respeito aos temas de estudo, Kessler (2007), em mapeamento dos trabalhos na América Latina, identificou análises que tratam sobretudo das relações familiares patriarcais, da centralidade da problemática da terra, das questões relacionadas à participação dos jovens no trabalho familiar, de tensões identitárias entre o local e o global e da decisão de jovens sobre permanecer no campo ou migrar. Outros autores mencionam o aumento do trabalho assalariado, a precarização das relações de trabalho, a crescente urbanização e a diminuição do trabalho familiar (Alvarado; Martínez Posada; Muñoz Gaviria, 2009; González Cangas, 2003; Jurado; Tobasura, 2012; Romero Cabrera, 2004). É sobre esses temas que vigora até os dias atuais o debate sobre a juventude rural no cenário latino-americano.

No Brasil, ainda no final da década de 90, parte da produção acadêmica sobre o tema juventude enfocava o contexto urbano, relacionado sobretudo com a educação, a sexualidade, os movimentos sociais e a socialização (Abramo, 1997; Melucci, 1997; Sposito, 1999). Para Weisheimer (2005), nesse mesmo período, pesquisadores brasileiros começaram a olhar para os jovens no universo rural em duas perspectivas: a participação dos jovens nas dinâmicas migratórias e a persistência do que chamou invisibilidade social. Estudiosos associaram a saída dos jovens do espaço rural ou a sua permanência nesse espaço ao contexto em que esses atores estariam inseridos, sobretudo em análises que privilegiaram a categoria trabalho e a reprodução social do grupo familiar (Camarano; Abramovay, 1998; Wanderley; 1999; Woortman, 1990).

Mais recentemente, os estudos sobre o tema têm abordado o dilema dos jovens entre sair do estabelecimento familiar e aí ficar (Malagodi; Marques, 2007), a questão de gênero, que relega jovens mulheres à invisibilidade, empurrando-as para outras ocupações (Stropasolas, 2006), os conflitos geracionais quanto à sucessão (Neves, 1997; Wanderley, 2007) e o desejo de autonomia (Marin; Redin; Costa, 2014; Mota, 2003).

$\mathrm{Na}$ literatura paraense, apesar da valiosa contribuição de Alves e Mota (2013), de Freire (2009), de Freire e Castro (2007) e de Silva (2008) sobre juventude, socialização e trabalho, persistem lacunas quanto à motivação dos jovens para o trabalho, problemática a que nos dedicamos neste artigo, num contexto em que a expansão de monocultivos de dendê tem indicado uma 
reconfiguração do mercado de trabalho, com o aumento da ocupação de jovens, predominantemente homens, no trabalho assalariado no Nordeste Paraense (Monteiro, 2015; Sampaio, 2014).

Nesse contexto de mudanças, consideramos necessário compreender os jovens em suas múltiplas faces, como grupos que são influenciados por transformações, situados em espaços sociais e temporalidades que lhes atribuem significados únicos (Freire, 2009).

\section{ATORES, PROCEDIMENTOS E LUGAR DE PESQUISA}

O nosso objetivo neste artigo é analisar a motivação de jovens, filhos de agricultores familiares, para o trabalho, tendo em conta o debate que evidencia o dilema entre "sair e ficar" no estabelecimento familiar e as evidências empíricas nos nossos primeiros contatos que indicam a predominância do desejo de "ficar" nas suas localidades de origem. Orientadas pelas sociologias do trabalho e rural, realizamos um estudo de caso na comunidade ${ }^{1}$ rural Perseverança, município de São Domingos do Capim, mesorregião do Nordeste Paraense (Figura 1). O lugar da pesquisa caracteriza-se pela coexistência da produção familiar (fruticultura e cultivo de mandioca, de pimenta-do-reino e de dendê) e empresarial (pecuária e dendê) num contexto de esgotamento do sistema de "corte e queima" 2 e de quase completa ausência do Estado, quanto aos serviços de extensão e de crédito para os agricultores familiares. Transformações recentes amparadas em políticas públicas para a expansão de monocultivos de dendê têm reconfigurado a paisagem localmente, muito embora não tenham refletido significativamente nas relações de trabalho, nem na oferta de postos de trabalho.

Figura 1 - Localização de Perseverança no Nordeste Paraense.

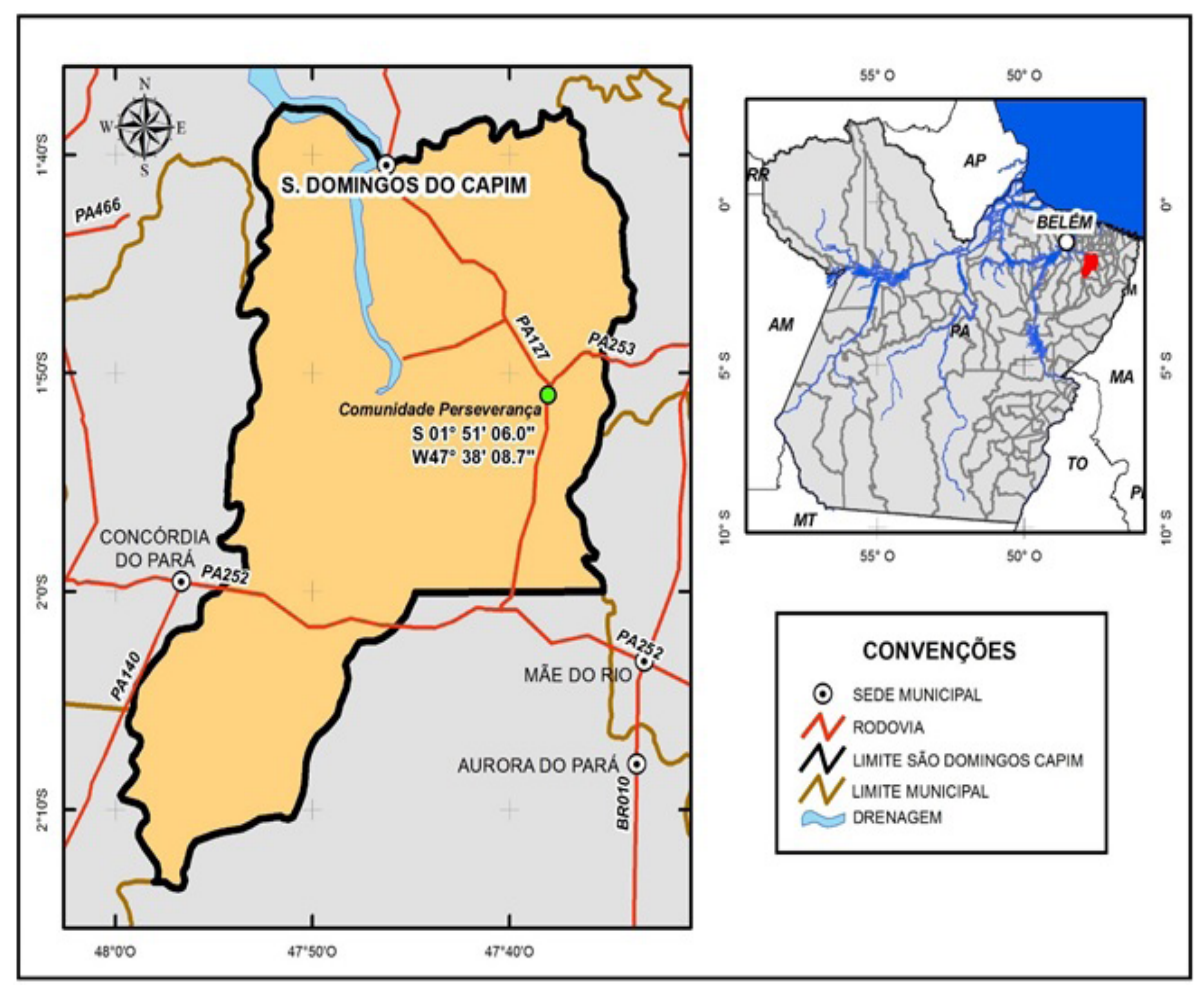

Fonte: Laboratório da Embrapa Amazônia Oriental

1 Comunidade, termo polissêmico, considerado neste artigo como sinônimo de localidade e adotado em respeito à denominação empregada pelos habitantes para se referirem ao local onde moram.

2 Referente à agricultura itinerante, sistema agrícola contínuo no qual clareiras são abertas por meio de queima para serem cultivadas por períodos mais curtos de tempo do que aqueles destinados ao pousio. 
A metodologia de pesquisa baseou-se na revisão da literatura e no levantamento de dados secundários e primários. Observações do cotidiano dos jovens no lazer e no trabalho foram realizadas, assim como entrevistas (semiestruturadas e abertas) com 60 jovens, dos quais 36 (60\%) eram rapazes e 24 (40\%) eram moças. A seleção dos jovens para as entrevistas deu-se pela indicação de alguns habitantes com os quais mantivemos contato, segundo a perspectiva local do que é "ser jovem" naquele contexto: quando as responsabilidades e os deveres ainda não se estabeleceram por completo no cotidiano, independentemente da idade. Ainda que haja predominância desse modo de pensar e de compreender a juventude entre os entrevistados, permanecem diferenças de percepção entre moças e rapazes sobre sentir-se como jovem ou encontrar-se na juventude, conforme se depreende dos seguintes depoimentos:

Uma pessoa jovem é aquela que não tem muita responsabilidade ainda, pode brincar, sem a responsabilidade de cuidar de uma família (J. A., moça, 22 anos). Eu tenho pra mim que jovem é aquele que ainda pode fazer tudo que quer que o corpo ainda aguenta (F. J., rapaz, 19 anos).

Eu acho que o jovem é mais ou menos aquela idade que vai até uns 20 anos, né? Eu não sei... Acho que já sou adulta porque eu já sou casada e tenho 2 filhos (M. J., moça, 26 anos).

As entrevistas versaram sobre a iniciação no trabalho, a divisão do trabalho no estabelecimento, as ocupações, o trabalho assalariado (tipos, incidência), as motivações para o trabalho, entre outros temas. Entrevistamos também cinco pessoas consideradas as residentes mais antigas, para traçar o histórico da comunidade. Para entender a visão dos pais sobre a inserção ocupacional dos jovens, seus filhos, entrevistamos 22 pessoas de diferentes famílias ali residentes.

Em nosso modelo de análise, compreendemos motivação como parte do conjunto de princípios básicos que representam necessidades (financeiras, de força de trabalho etc.) e motivos (desejo, falta de opção etc.) ou que também podem indicar a existência de alguma ordem dimensional relacionada a valores que são vistos como princípios-guia disponíveis para todos os seres humanos, podendo ser assumidos em magnitudes distintas, uma vez que emergem associados às experiências de socialização e dependem do contexto em que está inserida cada pessoa (Gouveia, 2003). A motivação depende também, segundo Bergamini (1990), da diversidade de interesses entre os indivíduos visto que as pessoas não fazem as mesmas coisas pelas mesmas razões. Para a autora, não é apropriado considerar o conceito de motivação como uma regra geral. Para Cerqueira (2004), o processo de construção da motivação sofre influência de outros fatores, de oportunidades educacionais, da vida profissional e da realidade de vida, fundamentais para a motivação que cada pessoa terá para realizar algo.

Metodologicamente, seguimos os três momentos que marcam a relação do jovem com o trabalho (Wanderley, 2013). No primeiro, na infância, a participação e o esforço no trabalho são reduzidos e expressam as relações de socialização e de aprendizado no seio familiar. No segundo, na juventude, existe um aumento do envolvimento no esforço do trabalho familiar, mesmo quando há conciliação de atividades com a educação formal. No terceiro, o jovem passa a desvincular-se de sua família em busca da realização de seus projetos individuais, que, em sua maioria, são acompanhados da emancipação dos seus pais e da formação de uma nova família.

A caracterização do trabalho foi feita por meio da identificação das atividades (remuneradas ou não), realizadas pelas moças e pelos rapazes. Foram consideradas diferenças e semelhanças quanto aos padrões incorporados desde a infância, à inserção no trabalho, à relação com a família, à dependência ou à autonomia que existe nas práticas realizadas por cada um deles e às suas condições sociais e econômicas. Desse modo, estão no centro da análise as motivações para ambos. 
Além da introdução, o artigo é composto de três partes: em primeiro lugar, aborda-se a socialização para o trabalho; em seguida, examinam-se as motivações dos jovens para o trabalho familiar e assalariado; finalmente, tecem-se as considerações finais.

\section{SOCIALIZAÇÃO PARA O TRABALHO: “DESDE PEQUENO EU JÁ AJUDAVA”}

Partimos da constatação de que a iniciação de jovens no trabalho é feita no seio da família, na qual a unidade de produção temporariamente coincide com a unidade de consumo e tem como principal base a reciprocidade das obrigações familiares (Garcia Júnior, 1983; Heredia; Cintrão, 2006; Redin, 2013). A criança é socializada e torna-se parte daqueles que aplicam um esforço comum para a realização das atividades na propriedade familiar.

Em Perseverança, a maioria dos jovens entrevistados (48 ou 80\%) afirmou que a iniciação no trabalho ocorreu juntamente com a família nos estabelecimentos familiares. Para os demais, a venda precoce da força de trabalho impôs-se antes dos 12 anos de idade.

Não obstante a diferença na socialização para o trabalho, os jovens entrevistados têm em comum a simultaneidade entre aprendizados ocupacionais e estudos na infância, como também constatado por Wanderley (2013) em pesquisa realizada com jovens rurais de Pernambuco, Nordeste do Brasil. A autora afirma ter constatado "que a educação formal ocupou a maior parcela do tempo dos jovens no período da infância por ser considerada de suma importância pela família no processo de formação dos filhos". Constatação similar fez Freire (2009) no Pará, Amazônia $^{3}$, ao concluir que a questão educacional formal não é tão grave nas famílias dos jovens camponeses, quando se considera a média nacional. Entre os jovens entrevistados em Perseverança, não foram encontrados casos de evasão escolar antes do término do ensino fundamental.

De maneira geral, os jovens de Perseverança, quando crianças, estudavam em uma parte do dia e realizavam as tarefas com a família na outra. Um rapaz bem descreveu sua rotina aos 9 anos de idade:

[...] falando assim de fazer as coisas quando a gente era criança, a gente aqui não fazia por necessidade, era mais pra acompanhar o pai e a mãe mesmo. De manhã a gente ia pra escola porque isso, sim, era a nossa obrigação, umas sete horas, a gente já estava no colégio. Umas onze horas, a gente já estava em casa e, depois de comer, se o pai voltasse pra roça ou se fosse fazer alguma coisa, a gente ia junto. Passava a tarde todinha com ele e assim a gente aprendeu a fazer tudo que sabe hoje... se eu sei as coisas tudo é porque eu estava no meio olhando e fazendo o que dava pra ajudar (A. C., 24 anos, rapaz).

Se a memória dos entrevistados evoca a simultaneidade entre trabalho e estudos na infância, o tema tem sido localmente motivo de polêmica nas últimas décadas em virtude da automática associação entre trabalho infantil e trabalho socialmente condenável. Não desconhecendo a deliberação da Organização Internacional do Trabalho (OIT) e do Estatuto da Criança e do Adolescente (ECA) quanto à proibição do trabalho a menores de quatorze anos de idade, salvo na condição de aprendiz ${ }^{4}$, o tema tem suscitado outras análises.

No Brasil, Neves (1999) foi uma das primeiras a analisar a questão sob a ótica da diferenciação entre trabalho socialmente condenável e trabalho não socialmente condenável, cha-

\footnotetext{
3 A pesquisa foi desenvolvida nos municípios do Baixo Tocantins, Igarapé-Miri e Moju, no Estado do Pará.

$4 \mathrm{O}$ artigo 60 do Estatuto da Criança e do Adolescente dispõe: "É proibido qualquer trabalho a menores de quatorze anos de idade, salvo na condição de aprendiz". Portanto, de acordo com esse artigo, o trabalho só é reconhecido em um caso específico: o de aprendiz. O artigo 62 do ECA assim define a aprendizagem do jovem: "Considera-se aprendizagem a formação técnico-profissional ministrada segundo as diretrizes e bases da legislação de educação em vigor”.
} 
mando a atenção para a tradição da formação ocupacional. Afirma a autora: "Transformando necessidade em virtude, a inserção laborativa prematura dos filhos exprime uma divisão familiar do trabalho [...]. Este sacrifício forçado valoriza a forma de participação na vida familiar [...]" (Neves, 1999, p. 52).

$\mathrm{Na}$ mesma perspectiva, Stropasolas (2012) ressalta as várias abordagens da inserção ocupacional de crianças e adolescentes, explicando que é fundamental haver diferenciação entre as atividades agrícolas desenvolvidas por crianças sob a ótica do trabalho familiar e do trabalho assalariado, visto que o modelo familiar pressupõe uma lógica única e diferenciada de outros processos produtivos nos espaços rurais.

Em concordância com os autores, analisamos a inserção das crianças no trabalho como parte do aprendizado ocupacional, da formação do caráter e também do suprimento de necessidades. Com tais propósitos, meninos e meninas apresentaram inserções distintas, fazendo parte de seu aprendizado desempenhar atividades culturalmente atribuídas aos gêneros e, por isso mesmo, sujeitas a um reconhecimento diferenciado.

\subsection{ENTRE ATIVIDADES NA CASA E NO CAMPO: MENINAS E MENINOS “AJUDAM” E “TRABALHAM”?}

Em se tratando da socialização para o trabalho, via de regra, as atividades estão divididas em domésticas e produtivas, associadas respectivamente à mãe e ao pai, à casa e ao campo. Dente as moças, 67\% (16) informou que a sua inserção ocupacional na infância se deu na esfera doméstica sob a orientação das suas mães, que transmitiam a rotina dos cuidados com a casa, tal qual uma preparação para o futuro. Dos 36 rapazes, 31 (86\%) dedicaram-se predominantemente às atividades ligadas à agricultura, com o pai. Nos dois casos (meninos e meninas), a iniciação ao trabalho se deu na infância, o que corresponde ao primeiro momento de trabalho identificado por Wanderley (2013).

Tomando em consideração o discurso, as afirmações dos jovens coincidem com as análises de Brumer (2004) e Weisheimer (2007) realizadas no Sul do Brasil. Weisheimer (2007), analisando a divisão do trabalho rural, verifica-se que os jovens homens desempenham tarefas com toda a família, com o pai ou sozinhos. Em determinada situação, cabe ao filho a responsabilidade exclusiva em atividades agrícolas mais simples; atividades desempenhadas por pai e filho são atividades consideradas mais difíceis, de certa forma a realização dessas atividades em conjunto é uma maneira de o pai ensinar o filho a lidar com atividades mais complexas no futuro. Brumer (2004) constatou que, diferentemente dos homens, as mulheres são responsáveis pelas atividades domésticas, nas quais, em geral, são auxiliadas ou substituídas pelas filhas, quando precisam realizar outras atividades. Com efeito, a maioria das mulheres foi iniciada no trabalho por meio dos cuidados com a casa.

As análises contribuem para conceber, grosso modo, a divisão do trabalho pelo prisma do gênero, e a consequência mais visível é a separação entre produção e reprodução, com diferente valorização para cada uma. Como afirma Hirata (2002, p. 280), a “[...] divisão social e técnica do trabalho é acompanhada de uma hierarquia clara do ponto de vista das relações sexuadas de poder". A autora enfatiza que, no âmbito dessa compreensão, aos homens é atribuído o campo produtivo e às mulheres, o reprodutivo.

Aguiar e Stropasolas (2010) constataram que, no espaço rural, o trabalho doméstico não é considerado "produtivo", por não possibilitar o acesso à renda, diferentemente do trabalho na agricultura, que permite a obtenção de uma renda direta e de produtos para o autoconsumo. Essa concepção expressa-se nas falas de muitas moças de Perseverança, que não identi- 
ficam as atividades domésticas como trabalho, mesmo que sua realização seja parte da rotina diária e dependam de habilidades apreendidas, de saberes, de dispêndio de energia e de tempo.

Por outro lado, é usual em Perseverança acreditar que a iniciação de meninas e meninos no trabalho está ligada à leveza ou ao peso das atividades, prenúncio do que farão nas suas vidas adultas. Para Paulilo (2004), a distinção entre trabalho "pesado", atribuído a homens, e trabalho "leve", a mulheres, está relacionada não à qualidade do esforço despendido nas atividades em si, mas ao sexo de quem as executa. Sua análise mostrou que, independentemente do trabalho realizado, a atividade é considerada leve se feita por mulheres, mesmo quando parece ser exaustiva, desgastante ou prejudicial à saúde.

Foge ao padrão da divisão do trabalho indicada para meninos e meninas o processo de fabricação de farinha de mandioca em Perseverança. Realmente, 78\% (47) dos entrevistados afirmaram ter participado dessa atividade com toda a família na infância. Essa particularidade deve-se ao fato de que a farinha de mandioca é um produto que se presta a uma dupla finalidade - venda e consumo -, além de agregar os diferentes membros da família simultaneamente numa mesma atividade; por outro lado, não há claramente diferenças entre o trabalho de homens e de mulheres (com exceção do chamado "torrador”, que é geralmente um homem contratado na base da diária). De acordo com Torres e Rodrigues (2010), a atividade também abarca trocas simbólicas que envolvem relações para além do parentesco e da amizade, tendo um alcance social, agregando solidariedade e ajuda mútua ao valor do trabalho.

Em concordância com as análises que contrastam produção e reprodução e os seus desdobramentos, questionamo-nos se os argumentos arrolados pelos entrevistados para justificarem as diferenças entre a socialização de meninos e meninas coincidem com as nossas observações. No cotidiano, observamos uma maior intersecção entre as atividades consideradas produtivas e reprodutivas do que os discursos permitem apreender.

Em várias famílias, as mulheres não realizavam apenas o trabalho da esfera doméstica e a dinâmica de organização das atividades apresentou mudanças em relação à situação geral na divisão sexual do trabalho. Há exemplos de meninos que participam dos cuidados com a casa para "ajudar” a mãe: “[...] eu acabei aprendendo a fazer comida e arrumar a casa, porque, como o meu pai não mora com a gente e não ajuda, minha mãe precisou trabalhar fora pra gente poder ter as coisas aqui, também cuido dos meus irmãos [..]” (W. T., rapaz, 15 anos).

No caso das meninas, observamos a realização simultânea de atividades na roça e de atividades domésticas, mesmo que isso não apareça em suas falas.

Eu gosto do trabalho na roça, só não gosto da lida de fazer farinha, porque é muito pesado [...], faz porque tem que fazer e a família precisa, mas sempre gostei do resto e quando dava eu ajudava, não no pesado, porque eu não dou conta de roçar, já tentei mas não dou conta de segurar na enxada não, a minha mãe sabe e já trabalhou muito, agora não é mais de roça, só cuida da casa. Mas pra hora de colher, eu pego pimenta, faço contas dos pés, porque aqui tem que contar porque tem gente que mexe, ajudar pra contar os que já estavam bom pra tirar... (I. S., moça, 18 anos).

O depoimento acima leva-nos a considerar que as atribuições são imaginariamente definidas para separar atividades de homens e mulheres. Na prática, entretanto, há maior diversidade de arranjos, mesmo que meninas acompanham suas mães e meninos acompanham seus pais mais frequentemente.

Em Perseverança, há uma divisão sexual do trabalho bem clara no que diz respeito à socialização, mas não existem impedimentos em relação ao gênero para a realização de 
determinado trabalho. Assim como analisado por Paulilo (2004), nos casos em que meninos e meninas assumem determinada tarefa de acordo com a necessidade da família, o reconhecimento da tarefa como trabalho ou como "ajuda" está diretamente ligado a quem o executa.

Em todos os casos, a motivação dos pais para o envolvimento das crianças nas atividades é a satisfação das necessidades da família simultaneamente ao aprendizado ocupacional por meio da socialização.

\section{3. “SERVIÇO DE JOVEM” EM PERSEVERANÇA: MOTIVAÇÃO PARA O TRABALHO}

$\mathrm{Na}$ literatura sobre juventude no espaço rural, autores reconhecem a importância do trabalho dos jovens para a manutenção de suas famílias e a reprodução social (Brumer, 2007; Capelo; Martins; Amaral, 2007; Costa; Ralish, 2013; Malagodi; Marques, 2007; Marin; Redin; Costa, 2014; Stropasolas, 2006; Wanderley, 2013) paralelamente aos estudos, o que corresponde ao segundo momento demarcado por Wanderley (2013) no que se refere à relação do jovem com o trabalho. Não obstante a importância desse trabalho, a partir de uma certa fase, os jovens permanecem no limiar entre a dependência do trabalho com a família e a sua emancipação, sentindo necessidade de terem a sua própria renda e de alcançarem autonomia. Com esse propósito, todos os 60 jovens entrevistados em Perseverança concentram-se no trabalho familiar ou alternam-se entre esse trabalho e o trabalho assalariado (Quadro 1), o que corresponde ao terceiro momento indicado por Wanderley (2013).

Quadro 1 - Tipos de trabalho de jovens em Perseverança, São Domingos do Capim (PA).

\begin{tabular}{|c|c|c|c|c|c|c|}
\hline \multirow{2}{*}{ Tipo DE TrabalHo } & \multicolumn{2}{|c|}{ RAPAZES (36) } & \multicolumn{2}{c|}{ MoçAS (24) } & \multicolumn{2}{c|}{ MoçAS E RAPAZES (60) } \\
\cline { 2 - 7 } & Absol. & $\%$ & Absol. & $\%$ & Absol. & $\%$ \\
\hline Somente trabalho familiar (STF) & 11 & 30,6 & 10 & 42 & 21 & 35 \\
\hline Somente trabalho assalariado (STA) & 04 & 11,1 & 07 & 29 & 11 & 18 \\
\hline Trabalho familiar e assalariado (TFA) & 21 & 58,3 & 07 & 29 & 28 & 47 \\
\hline
\end{tabular}

Fonte: Pesquisa de campo (2016).

Como mostram os dados, as ocupações dos jovens (rapazes e moças) se diferenciam em todos os tipos de engajamento no trabalho, como analisaremos a seguir. Para tal, adotamos uma tipologia como recurso analítico.

\subsection{MOTIVAÇÃO PARA SOMENTE TRABALHO FAMILIAR (STF)}

Por trabalho familiar, compreendemos o trabalho realizado entre os membros da família sem compensações mercantis (remuneração, salário), que é regido por valores, como o propósito da reprodução social, o aprendizado profissional, a reciprocidade das obrigações familiares e hierarquias, segundo uma organização do trabalho baseada em fundamentos culturais, sexuais e geracionais. O produto desse trabalho é resultado do esforço conjunto dos integrantes da família.

Para o trabalho somente com a família, os dados diferem quando comparamos as moças e os rapazes, sendo realizado por 42\% (10) e 30\% (11) dos jovens, respectivamente. Eles estão na faixa de 23 a 26 anos. As explicações para que ambos os grupos realizem STF indicam 
que as moças permanecem mais frequentemente no estabelecimento familiar porque a educação oferecida em Perseverança (até o ensino médio) atende às suas expectativas e às de suas famílias, sem que elas precisem migrar para a sede do município ou para outra cidade para continuar os estudos.

Para 67\% (16) das moças entrevistadas, não faz parte de seu projeto de vida o ingresso em uma universidade. Além disso, dificuldades financeiras, a falta de oportunidades de assalariamento fora do âmbito doméstico e a necessidade de “ajudar" a família no estabelecimento fazem com que elas permaneçam. Essa constatação vai de encontro a estudos que apontam que as moças migram mais facilmente para trabalhar e estudar (Brumer, 2004; Stropasolas, 2006; Weisheimer, 2007).

Nesse sentido, os diferentes engajamentos no trabalho familiar atendem a uma necessidade enquanto princípio básico da motivação para as moças. A ordem dimensional relaciona$\mathrm{da}$ a um valor ainda frequente naquele contexto é que o trabalho externo na agricultura (maior parte dos postos quando disponíveis) é mais adequado a homens pelos deslocamentos, pela estadia em alojamentos com outros homens etc. Com tais distintivos associados a juízos morais, as jovens moças predominam no STF (que não se restringe ao âmbito doméstico), muito embora almejem o trabalho assalariado, mas não na agricultura. Nos estabelecimentos familiares, elas dedicam-se predominantemente aos cuidados com a casa, à criação de pequenos animais, ao trabalho de fazer farinha e às práticas agrícolas em hortas, pomares e nas demais culturas que possam existir na propriedade.

O meu trabalho aqui mesmo é o da casa, de resto é mais a ajuda quando as coisas estão aperreadas porque a minha sogra tem problema na coluna e não vai mais. Às vezes o meu sogro precisa que eu vá lá ajudar a fazer uma coisa ou outra, porque os meninos estão trabalhando pro vizinho aqui de trás. [...] E o que eu sei fazer? Na roça de tudo um pouco, porque na casa do meu pai nós fomos criados na roça mesmo... mas aqui é mais a parte da farinha e de ajudar a olhar... (R. V. moça, 20 anos).

Quanto aos rapazes, as motivações para trabalhar somente com a família são outras. Quase a totalidade deles - 82\% (17) - teve experiência com o trabalho assalariado nos arredores de Perseverança, mas preferiu o trabalho com a família por considerar que o salário não compensa as dificuldades passadas e o esforço empreendido nas tarefas, especialmente no trabalho nas empresas de dendê. Informou um entrevistado:

Quando a empresa chegou aqui, em 2011 mais ou menos, um monte de gente foi lá pra trabalhar, teve muito interesse [...] eu mesmo trabalhei 3 meses direto... mas era muito pesado e não tinha sol e nem chuva, e ainda descontavam... A empresa também não pagou direito o combinado, que era de pagar em 15 dias logo, muita gente saiu logo nessa hora, eu aguentei mais um tempo, mas depois vi que o mínimo que eu tirava lá não compensava não, porque demorava muito pra fazer um dinheiro pouco, que não dava nem pra ajudar em casa. [O pai interferiu explicando que conversou com o filho sobre a roça dar o que comer e não precisar comprar nada]. É [...] aqui o que a gente come tem, não dá pra luxar com nada, mas comida sempre tem porque é do nosso terreno (A. C. rapaz, 25 anos).

A flexibilidade de horário possibilitada pela autonomia na organização do trabalho na agricultura familiar é diferente do rigor do trabalho assalariado formal e aparece como elemento motivador para a permanência dos jovens no trabalho com a família. Nesse sentido, verifi- 
camos que algumas características do assalariamento (obrigatoriedades controladas por terceiros) fazem com que ele seja visto pelas pessoas socializadas no âmbito das relações familiares de produção como um aprisionamento (Mota, 2003).

Entre os que pertencem ao grupo STF, 63\% (7) dos rapazes e 90\% (9) das moças afirmaram que a sua permanência na comunidade se deve à falta de oportunidades profissionais mais interessantes do que o trabalho assalariado na agricultura, porque consideram que não têm qualificação ou experiência. Chama a atenção o fato de habitarem na região mais antropizada do Estado do Pará, cuja atividade central é a agricultura que, diferentemente de outros segmentos, conta com incentivos públicos, sob o argumento do desenvolvimento regional. Entretanto, os postos de trabalho gerados não evidenciam mudanças. Ademais, contribuem para que os jovens socializados na agricultura e com maior nível de escolaridade do que os seus pais atribuam a si mesmos as razões da não ocupação fora do estabelecimento, e não a um contexto de precarização e de crescente perda de direitos trabalhistas.

A totalidade das moças e rapazes também afirma querer viver no espaço rural, mas os jovens não pretendem trabalhar com a agricultura à semelhança dos seus pais em razão da penosidade do trabalho e dos ganhos incertos. O desejo para o futuro alterna-se entre a administração da propriedade familiar e a abertura de um comércio em outras bases (mão de obra terceirizada e tecnologia).

Os jovens também são motivados pelo desejo de continuar a viver perto de suas famílias e dizem-se "acostumados" com o trabalho. Pretendem continuar vivendo na comunidade e no trabalho familiar, têm como motivação principal aspectos relacionados à valorização da localidade de origem: cada um é uma pessoa que tem raízes e faz parte de uma família cujo endereço todos conhecem e na qual "nasceu e foi criado" (CARNEIRO, 2007).

\subsection{MOTIVAÇÃO PARA SOMENTE TRABALHO ASSALARIADO (STA)}

Consideramos trabalho assalariado toda atividade remunerada cujo fundamento está em acordos mercantis de venda da força de trabalho, podendo ser realizado de maneira legal (regular ou ocasional, mas regido pelas leis trabalhistas) ou informal (regular ou ocasional, independentemente de formalidades contratuais).

No que se refere a STA, dos entrevistados em Perseverança, 11\% (4) dos rapazes estavam nessa condição, tinham idades entre 22 e 28 anos e, em termos de escolaridade, todos haviam concluído o ensino médio.

Embora os jovens tenham em comum a condição do trabalho exclusivamente assalariado, diferenciam-se pelas relações que vivenciam. Enquanto todos os rapazes têm contratos regidos pela Consolidação das Leis do Trabalho (CLT) ${ }^{5}$, trabalhando como funcionário da prefeitura municipal (vigilante), mecânico de trator numa agroindústria de dendê e vendedores no comércio local, as moças estão submersas em relações informais, sem direitos trabalhistas e com salários que dependem de acertos, e suas atividades podem variar segundo a demanda da família empregadora (cozinhar, fazer faxina e cuidar de crianças (babá)). Para além das diferenças que explicitam a influência do gênero nas qualificações, rapazes e moças têm em comum a motivação para terem ganhos regulares e contínuos.

Eles explicam que o objetivo do TSA é a “carteira assinada”, o que possibilita o planejamento futuro para a aquisição de bens de consumo, o investimento no estudo e até mesmo o casamento, além do prestígio associado à responsabilidade. Afirma um dos jovens assalariados:

5 A Consolidação das Leis do Trabalho (CLT), aprovada pelo Decreto-Lei n. ${ }^{\circ} 5.452$, de $1 .^{\circ}$ de maio de 1943 , foi sancionada pelo então presidente Getúlio Vargas, unificando toda a legislação trabalhista existente no Brasil. 
Trabalhar de salário é segurança, porque na prefeitura se tem o certo no mês, fora o décimo terceiro [...]. Se tem doença séria, não é descontado. Se não fosse esse trabalho, eu não ia ter nem como casar e nem fazer a minha faculdade de educação física. Ia ter que sair daqui de Perseverança, ia ter que ir pra Castanhal arrumar um trabalho pra poder estudar (J. M., rapaz, 25 anos).

Esse depoimento revela que a motivação para continuar nessa atividade está ligada à segurança financeira: o jovem anseia ter um salário fixo, custear os estudos do ensino superior e ainda permanecer na comunidade, próximo da família, mantendo seu estilo de vida. Para além da segurança e do salário, evidenciam-se valores associados ao modo de vida.

A motivação das moças para a realização desse trabalho relaciona-se principalmente com a busca de independência financeira. Porém, assim como observado na pesquisa de Alves e Dayrell (2015) sobre jovens rurais do município de Governador Valadares em Minas Gerais, em Perseverança as possibilidades de conquistar alguma autonomia financeira são escassas para elas.

Ainda entre as moças, a motivação para o trabalho assalariado é atribuída à insatisfação com o papel que desempenham nas atividades rurais, no âmbito das relações estabelecidas entre homens e mulheres na organização do trabalho na produção familiar, principalmente em razão da falta de reconhecimento das atividades realizadas em casa, que não são consideradas trabalho. Além disso, as moças consideram o serviço doméstico chato e repetitivo. Segundo Brumer (2007), Stropasolas (2006) e Weisheimer (2007), o desejo das jovens mulheres rurais de mudar do campo para a cidade, do trabalho familiar para o trabalho assalariado é fruto dos papéis sociais que elas assumem no modo de vida camponês. Esses autores destacam que a função desempenhada por moças é muitas vezes caracterizada como "ajuda”, o que imprime uma certa invisibilidade ao trabalho desempenhado por elas, suscitando uma insatisfação com a vida rural. Do total de 24 moças entrevistadas, 75\% (18) manifestaram a vontade de realizar uma atividade profissional assalariada diferente do trabalho doméstico.

Em todos os casos, os jovens encontram-se naquele momento demarcado por Wanderley (2013), no qual a emancipação da família e o casamento constam nos seus projetos no curto prazo.

Sobre as motivações individuais dos jovens para o trabalho assalariado, Mota (2003) constatou que o trabalho assalariado é tido como fonte de segurança e de reconhecimento social. Em sua pesquisa com trabalhadores assalariados, a autora chegou à seguinte conclusão:

No discurso, o trabalho registrado está valorizado pelos benefícios legais. Tem também o aspecto do reconhecimento da ocupação e de certa tranquilidade em ter um salário por um período mais longo, o que permite se programar financeiramente. É a celebração de que o trabalhador está aprovado profissional e socialmente pelos vínculos exercitados no trabalho, além de ser um testemunho escrito da trajetória do mesmo que pode ser utilizado como diferencial em relação a outros trabalhadores (Mota, 2003, p. 181).

Nessa perspectiva, o trabalho assalariado representa a oportunidade para que os jovens realizem suas necessidades, como a consolidação dos seus projetos individuais, muitas vezes diferentes daqueles desejos relativos aos projetos da família (Brumer, 2007; Costa; Ralish, 2013; Stropasolas, 2006; Weisheimer, 2007).

\subsection{MOTIVAÇÃO PARA O TRABALHO FAMILIAR E ASSALARIADO (TFA)}

Consideramos que somente os 28 jovens que se alternam entre trabalho familiar e assalariado (TFA) fazem parte desse grupo. Como nos demais grupos precedentes, as diferenças 
de engajamento de moças e rapazes chamam a atenção: 29\% (7) e 58\% (21), respectivamente. Nesse tipo, concentra-se o maior número do total de jovens entrevistados (28, ou seja, 47\%), o que, de algum modo, sugere o dilema entre "sair e ficar" no estabelecimento familiar e conviver com a família, tema frequente na literatura.

Para designar o conjunto de atividades ocasionalmente realizadas por esses jovens fora do estabelecimento, tomamos emprestada a denominação local - "bicos" -, usada para se referir a algo realizado apenas ocasionalmente e com previsão de término. Os tipos de atividades nas quais os "bicos” ocorrem estão explicitadas no Quadro 2.

Quadro 2 - Trabalhos remunerados realizados ocasionalmente por jovens em Perseverança (PA).

\begin{tabular}{|c|c|c|c|c|c|c|}
\hline \multirow{2}{*}{ Tipos de trabalHo } & \multicolumn{2}{|c|}{ Rapazes (21) } & \multicolumn{2}{c|}{ MoçAs (7) } & \multicolumn{2}{c|}{ TOTAL (28) } \\
\cline { 2 - 8 } & Absol. & $\%$ & Absol. & $\%$ & Absol. & \% \\
\hline Trabalho na agricultura (diarista) & 12 & 58 & - & - & 12 & 42 \\
\hline Ajudante de pedreiro & 08 & 38 & - & - & 08 & 28 \\
\hline Prestação de serviços para internet & - & - & 01 & 14 & 01 & 04 \\
\hline Atendente de lanchonete & - & - & 01 & 14 & 01 & 04 \\
\hline Cabeleireiro & 01 & 04 & 03 & 43 & 04 & 14 \\
\hline Manicure & - & - & 02 & 29 & 02 & 08 \\
\hline TOTAL & 21 & 100 & 07 & 100 & 28 & 100 \\
\hline
\end{tabular}

Fonte: Pesquisa de campo (2016).

Em relação ao conjunto de atividades realizadas, destaca-se a alternância entre o trabalho familiar na propriedade dos pais e o assalariamento em propriedades (agrícolas ou não) e negócios de terceiros, nos quais os jovens realizam "bicos" cuja remuneração atende a necessidades individuais e familiares. Os jovens inseridos nessas relações de trabalho têm idades entre 15 e 30 anos e escolaridade que varia entre o $6 .^{\circ}$ ano do ensino fundamental e o ensino médio.

A motivação central para a alternância entre trabalho familiar e assalariado (TFA) é a obtenção de renda para as necessidades pessoais. Entretanto, o montante de recursos recebido não possibilita a independência dos pais e, por isso, os jovens seguem residindo com os pais e participando de atividades que asseguram a sobrevivência do grupo familiar. Rapazes e moças reconhecem que há incentivo para que eles trabalhem ocasionalmente para terceiros, porque isso reduz a pressão sobre os pais para obterem recursos para adquirir artigos de uso pessoal.

Como demonstramos no Quadro 2, existem atividades realizadas somente por rapazes (diarista na agricultura e ajudante de pedreiro), outras, somente por moças (prestação de serviços para internet, atendente de lanchonete e manicure) e outras ainda realizadas pelos dois grupos (cabelereiro). O trabalho assalariado ocasional na agricultura é realizado exclusivamente por rapazes e ocorre em propriedades de fazendeiros, especialmente no cultivo da pimenta-do-reino, na fruticultura, na dendeicultura, mas também em estabelecimentos familiares de terceiros.

A remuneração dessas atividades para rapazes e moças é estabelecida de três maneiras. $\mathrm{Na}$ primeira, o jovem é pago por meio de diárias, recebendo um valor estipulado por dia de trabalho: a quantia monetária recebida varia de acordo com o número de dias trabalhados. $\mathrm{Na}$ segunda - a empreita ou o "trabalho alugado" -, a remuneração pode ser definida de acordo com o período em que o trabalho foi realizado ou de acordo com a tarefa executada. Na terceira, o jovem recebe um valor pelo trabalho realizado (manicure e cabeleireiro, por exemplo).

No grupo TFA, 100\% das moças afirmaram realizar atividades familiares como obrigação em casa, mesmo enquanto exercem atividades remuneradas fora. Para os rapazes, essa rea- 
lidade é diferente. O trabalho familiar no estabelecimento dos pais que se alterna com o trabalho assalariado é sempre relacionado à agricultura.

Nesse grupo, tanto os rapazes como as moças deixaram claro que se sentem insatisfeitos com as atividades realizadas com a família porque estão subordinadas à liderança dos pais. A insatisfação é uma das motivações para o desejo de mudança.

Quando entrevistados sobre seus objetivos futuros, os jovens manifestaram o desejo de sair da comunidade para dar continuidade aos estudos, cursar uma formação superior, ou trabalhar assalariado em outro município que ofereça oportunidades tidas como melhores. Nesse sentido, não se pode considerar a escolha de outras profissões por parte dos jovens como um momento de rompimento com os pais e os projetos de influência familiar. Explica Wanderley (2013, p. 206):

A escolha de outras profissões, fora da agricultura, recebe, igualmente, uma forte influência familiar, dependendo, nesse sentido, de decisões tomadas internamente no seio da família. Porém, ela depende igualmente das oportunidades oferecidas no próprio local ou da disposição dos jovens para se deslocarem temporária ou permanentemente.

No caso das moças, o investimento temporal nos estudos significa a perspectiva de inserção no mercado de trabalho não agrícola, a possibilidade de tornar realidade o projeto de vida, no qual não há continuidade do trabalho na propriedade na fase adulta. Weisheimer (2007) vê esse movimento de valorização dos estudos por parte da maioria das moças como uma estratégia de mudança de vida. Entretanto, em Perseverança, elas permanecem na comunidade e não migram, mesmo quando estudam mais. Essa permanência deve-se à falta de oportunidades externas e à satisfação com a vida local.

No caso dos rapazes de um modo geral, a motivação para a mudança é explicada por Paulilo (2004), que destaca a dificuldade que os rapazes têm de assumir a responsabilidade pelas atividades da propriedade sob a responsabilidade do pai. Geralmente, essa responsabilidade só é assumida pelos rapazes quando o pai se retira do trabalho, o que nem sempre acontece no momento de sua aposentadoria, pois a renda advinda da aposentadoria passa a ser uma complementação para a renda familiar, mas ele continua trabalhando. Assim, o pai continua como o ator principal nas tomadas de decisão relativas ao trabalho e à administração da propriedade rural. Diferentemente, as moças não pretendem substituir as suas mães. Desse modo, o desejo de partida é atribuído, por um lado, ao não protagonismo dos rapazes e, por outro, à rejeição das moças ao trabalho predominantemente doméstico. Assim, não são somente as dificuldades econômicas que motivam as saídas da família e da comunidade.

\section{CONSIDERAÇÕES FINAIS}

O objetivo do artigo foi analisar a motivação de jovens, filhos de agricultores familiares, para o trabalho, à luz do debate que evidencia o dilema entre "sair ou ficar" no estabelecimento familiar. As evidências empíricas desta pesquisa indicavam a predominância do desejo dos jovens de "ficar" nas suas localidades de origem. A pesquisa foi realizada por meio de um estudo de caso em Perseverança, São Domingos do Capim, mesorregião Nordeste Paraense.

Grosso modo, concluímos que a relação dos jovens com o trabalho é construída socialmente segundo os marcadores indicados por Wanderley (2013): na infância, quando ocorre a socialização para o trabalho, e na juventude, quando dois momentos se sucedem com maior envolvimento nas atividades familiares paralelamente ao estudo e com o investimento dos jo- 
vens nos seus projetos individuais, que envolvem a emancipação dos pais e a constituição de uma família.

Constatamos três tipos de engajamento de jovens no trabalho com suas respectivas motivações: a dedicação somente ao trabalho familiar (STF); a dedicação somente ao trabalho assalariado (STA); a alternância entre trabalho familiar e assalariado (TFA). No primeiro grupo, as motivações de rapazes e moças coincidem quanto à necessidade de contribuição para o trabalho familiar, à proximidade da família e da localidade. Entretanto, diferenciam-se na realização do trabalho, com os rapazes apontando a possibilidade de flexibilização e de gestão do próprio tempo. No segundo grupo, a obtenção de renda destaca-se como a maior motivação para a busca do atendimento de necessidades individuais e familiares e, paralelamente, do custeio dos estudos. Diferenciam-se rapazes e moças quanto aos direitos trabalhistas, porque se trata de uma condição que elas não vivenciam. No terceiro grupo, a motivação central para o trabalho é o desejo de obtenção de renda própria para despesas pessoais.

Quanto ao engajamento no trabalho, concluímos que há diferenças importantes de motivação entre rapazes e moças, assim como entre os tipos de trabalho que desempenham. Os rapazes predominam no TFA e as moças, no STF. Por motivações individuais e familiares, forma-se um padrão segundo o qual os homens são mais incentivados a "sair", porque mais facilmente ocupam postos de trabalho na agricultura, e as moças são mais incentivadas a "ficar".

A nossa conclusão foi reforçada pelos dados relativos ao trabalho assalariado porque, ainda que as moças se assalariem mais frequentemente, o lugar de trabalho é a própria comunidade, contrariando tendências observadas em outros estudos que indicam o assalariamento delas em outros lugares que não os de residência da família. Não obstante, elas rejeitam o trabalho doméstico, quer seja pela repetição, quer seja pela pouca valorização social.

Quanto aos tipos de trabalho, há trabalhos desempenhados exclusivamente por rapazes (diarista na agricultura e ajudante de pedreiro), outros, por moças (atendente de lanchonete, serviços de internet e manicure) e outros, por ambos os grupos (cabeleireiro). Atributos como delicadeza e peso do trabalho são associados, respectivamente, a moças e rapazes, o que reforça valores assumidos nos processos de socialização de ambos para o trabalho.

Conforme sugerido pela literatura, as motivações dos jovens para o trabalho em Perseverança devem-se a certa insatisfação com a agricultura, quer seja pela penosidade do trabalho, quer seja pelos ganhos incertos. Assim, concluímos que a motivação para o trabalho predominantemente assalariado nasce do desejo de ter uma renda para investimento em diferentes projetos de autonomia, como a formação universitária para a obtenção de emprego mais especializado na agricultura e para a aquisição de terra e comércio.

Concluímos, inspiradas em Cerqueira (2004), que o processo de construção da motivação em Perseverança sofre influência do desejo dos pais de garantirem um futuro menos vulnerável para os seus filhos, longe da agricultura praticada no momento da pesquisa. A motivação também é influenciada pelas condições do mercado local de trabalho que, além de ofertar poucos e precários empregos, é considerado pouco remunerativo, e pela condição do gênero, que incentiva a permanência das moças sob o argumento da inconveniência moral das suas saídas do âmbito familiar. Não obstante os argumentos, concluímos que há satisfação dos jovens com a vida social local e que eles são motivados a viabilizar a sua permanência sob outras condições que não a dos seus pais. 


\section{REFERÊNCIAS}

ABRAMO, Helena Wendel. Considerações sobre a tematização social da juventude no Brasil. Revista Brasileira de Educação, Rio de Janeiro, n. 5-6, p. 25-36, 1997.

AGUIAR, Vilênia Venâncio Porto; STROPASOLAS, Valmir Luiz. As problemáticas de gênero e geração nas comunidades rurais de Santa Catarina. In: SCOTT, Parry; CORDEIRO, Rosineide; MENEZES, Marilda (Org.). Gênero e geração em contextos rurais. Florianópolis: Mulheres, 2010. p. 157-181.

ALVARADO, Sara Victoria; MARTÍNEZ POSADA, Jorge Eliécer; MUÑOZ GAVIRIA, Diego Alejandro. Contextualización teórica al tema de las juventudes: una mirada desde las ciencias sociales a la juventud. Revista Latinoamericana de Ciencias Sociales, Niñez y Juventud, Manizales, v. 7, n. 1, p. 83$102,2009$.

ALVES, Ketiane dos Santos; MOTA, Dalva Maria da. Trabalho familiar ou assalariamento? Dilema de jovens em comunidades rurais. Novos Cadernos NAEA, Belém, PA, v. 16, n. 1, p. 163-180, jun. 2013.

ALVES, Maria Zenaide; DAYRELL, Juarez. Ser alguém na vida: um estudo sobre jovens do meio rural e seus projetos de vida. Educação e Pesquisa, São Paulo, v. 41, n. 2, p. 375-390, abr./jun. 2015.

BERGAMINI, Cecília Whitaker. Motivação: mitos, crenças e mal-entendidos. Revista de Administração de Empresas, São Paulo, v. 30, n. 2, p. 23-34, abr./jun. 1990.

BRUMER, Anita. Gênero e agricultura: a situação da mulher na agricultura do Rio Grande do Sul. Estudos feministas, Florianópolis, v. 12, n. 1, p. 205-227, jan./abr. 2004.

BRUMER, Anita. A problemática dos jovens rurais na pós-modernidade. In: CARNEIRO, Maria José; CASTRO, Elisa Guaraná. Juventude rural em perspectiva. Rio de Janeiro: Mauad X, 2007. p. 35-51.

CAMARANO, Ana Amélia; ABRAMOVAY, Ricardo. Êxodo rural, envelhecimento e masculinização no Brasil: panorama dos últimos cinquenta anos. Revista Brasileira de Estudos de População, Brasília, DF, v. 15, n. 2, p. 45-65, 1998.

CAPELO, Maria Regina Clivati; MARTINS, Suely Aparecida; AMARAL, Wagner Roberto do. Juventudes do campo: refazendo caminhos pesquisados. In: JEOLÁS, Leila Sollbeger; PAULILO, Maria Angela Silveira; CAPELO, Maria Regina Clivati (Org.). Juventudes, desigualdades e diversidades: estudos e pesquisas. Londrina: Eduel, 2007. p. 205-258.

CARNEIRO, Maria José. Juventude e novas mentalidades no cenário rural. In: CARNEIRO, Maria José; CASTRO, Elisa Guaraná de (Org.). Juventude rural em perspectiva. Rio de Janeiro: Mauad X, 2007. p. 53-79.

CERQUEIRA, Teresa Cristina Siqueira. O autoconceito e a motivação na constituição da subjetividade: conceitos e relações. InterMeio: Revista do Programa de Pós-Graduação em Educação-UFMS, Campo Grande, MS, v. 10, n. 20, p. 30-41, 2004.

COSTA, Fernando Luis Martins; RALISCH, Ricardo. A juventude rural do assentamento Florestan Fernandes no município de Florestópolis (PR). Revista de Economia e Sociologia Rural Piracicaba, Brasília, DF, v. 51, n. 3, p. 415-432, jul./set. 2013.

DURSTON, John. Juventud y desarrollo rural: marco conceptual y contextual. Santiago de Chile: Comisión Económica para América Latina y el Caribe, 1998.

FREIRE, Jacqueline Cunha da Serra. Juventude camponesa e politicas públicas: pertinência social do Programa Saberes da Terra na Amazônia paraense. Belém, PA, 2009. Tese (Doutorado em Desenvolvimento Sustentável) - Núcleo de Altos Estudos Amazônicos, Universidade Federal do Pará, Belém, PA, 2009.

FREIRE, Jaqueline Cunha da Serra; CASTRO, Edna. Juventude na Amazônia paraense: identidade e cotidiano de jovens assentados da reforma agrária. In: CARNEIRO, Maria José; CASTRO, Elisa Guaraná de (Org.). Juventude rural em perspectiva. Rio de Janeiro: Mauad X, 2007. p. 215-236.

GARCIA JÚNIOR, Afrânio Raul. Terra de trabalho: trabalho familiar de pequenos produtores. Rio de Janeiro: Paz e Terra, 1983. 
GONZÁLEZ CANGAS, Yanko. Juventud rural: trayectorias teóricas y dilemas identitarios. Nueva Antropología, Mexico, v. 19, n. 63, p. 153-175, 2003.

GOUVEIA, Valdiney V. A natureza motivacional dos valores humanos: evidências acerca de uma nova tipologia. Estudos de Psicologia, Natal, v. 8, n. 3, p. 431-443, 2003.

HEREDIA, Beatriz Maria Alásia de; CINTRÃO, Rosângela Pezza. Gênero e acesso a políticas públicas no meio rural brasileiro. Revista Nera, Presidente Prudente, ano 9, n. 8, p. 1-28, jan./jun. 2006.

HIRATA, Helena. Nova divisão sexual do trabalho? Um olhar voltado para a empresa e a sociedade. São Paulo: Boitempo, 2002. 336 p.

JURADO, Claudia; TOBASURA, Isaías. Dilema de la juventud en territorios rurales de Colombia: ¿ campo o ciudad? Revista Latinoamericana de Ciencias Sociales, Niñez y Juventud, Manizales, v. 10, n. 1, p. 63-77, 2012.

KESSLER, Gabriel. Juventud rural en América latina: panorama de las investigaciones actuales. In: BRUNIARD, Rogelio (Coord.). Educación, desarrollo rural y juventud: la educación de los jóvenes de provincias del NEA y NOA en Argentina. Argentina: UNESCO-IIPE, FIDA, SAGPA, 2007. p. 16-67.

MALAGODI, Edgard; MARQUES, Roberto. Para além de ficar ou sair: as estratégias de reprodução social de jovens em assentamentos rurais. In: CARNEIRO, Maria José; CASTRO, Elisa Guaraná de (Org.). Juventude rural em perspectiva. Rio de Janeiro: Mauad X, 2007. p. 197-214.

MARIN, Joel Orlando Bevilaqua; ANDREU, Fátima. Juventud rural: una invención del capitalismo industrial. Estudios Sociológicos, México, v. 27, n. 80, p. 619-653, maio/ago. 2009.

MARIN, Joel Orlando Bevilaqua; REDIN, Ezequiel; COSTA, Felipe Ferrari da. Juventude rural e trabalho no cultivo do tabaco. Revista Latino-Americana de Estudos do Trabalho, ano 19, n. 31, p. 159194, 2014.

MELUCCI, Alberto. Juventude, tempo e movimentos sociais. Revista Brasileira de Educação, Rio de Janeiro, n. 5-6, p. 5-14, 1997.

MONTEIRO, Marcílio de Abreu. Mudar para persistir: uma experiência de resistência camponesa e a expansão do dendê na Amazônia. In: SEMINÁRIO INTERNACIONAL AMÉRICA LATINA: POLÍTICA E CONFLITOS CONTEMPORÂNEOS, 2015, Belém, PA. Anais... Belém, PA: GETTAM: NAEA: UFPA, 2015. p. 246 a 260.

MOTA, Dalva Maria da. Trabalho e sociabilidade em espaços rurais: os trabalhadores da fruticultura do Platô de Neópolis. Recife, 2003. 282 f. Tese (Doutorado em Sociologia) - Universidade Federal de Pernambuco, Recife, 2003.

NEVES, Delma Pessanha. Agricultura familiar e mercado de trabalho. Estudos sociedade e a agricultura. Revista Estudos Sociedade e Agricultura, Rio de Janeiro, ano 5, n. 8, p. 7-24, abr./set. 1997.

NEVES, Delma Pessanha. A perversão do trabalho infantil: lógicas sociais e alternativas de prevenção. Niterói: Intertexto, 1999. 241 p.

PAULILO, Maria Ignez S. Trabalho familiar: uma categoria esquecida de análise. Revista Estudos Feministas, Florianópolis, v. 12, n. 1, p. 229-252, jan./abr. 2004.

REDIN, Ezequiel. Trabalho na roça e organização da produção da família rural. Geoingá: Revista do Programa de Pós-Graduação em Geografia, Maringá, v. 5, n. 2 , p. 166-186, 2013.

ROMERO CABRERA, Juan Ignacio. La modernización agraria en el Uruguay: los jóvenes rurales, una asignatura pendiente. In: GIARRACA, Norma; LEVY, Bettina (Comp.). Ruralidades latinoamericanas: identidades y luchas sociales. Buenos Aires: CLACSO, 2004. p. 163-201.

SAMPAIO, Iran Costa. A agricultura familiar e a agroindústria do dendê no município de Tomé Açu (PA): efeitos da agricultura por contrato na produção e no trabalho familiar. Belém, PA, 2014. 197 f. Dissertação (Mestrado em Sociologia e Antropologia) - Instituto de Filosofia e Ciências Humanas, Universidade Federal do Pará, Belém, PA, 2014.

SILVA, Márcia Cristina Lopes e. Da casa da família à casa da escola: dimensões de gênero na experiência educativa em alternância no município de Cametá-Pará. Belém, PA, 2008. 118 f. Dissertação (Mes- 
trado em Agricultura Familiar e Desenvolvimento Sustentável) - Universidade Federal do Pará, Belém, PA, 2008.

SPOSITO, Marília Pontes. Educação e juventude. Educação em Revista, Belo Horizonte, v. 26, p. 7-14, 1999.

STROPASOLAS, Valmir Luiz. O mundo rural no horizonte dos jovens: o caso dos filhos(as) de agricultores familiares de Ouro/SC. Florianópolis: UFSC, 2006. 346 p.

STROPASOLAS, Valmir Luiz. Trabalho infantil no campo: do problema social ao objeto sociológico. Revista Latino-Americana de Estudos do Trabalho, ano 17, v. 27, p. 249-286, 2012.

TORRES, Iraildes Caldas; RODRIGUES, Luana Mesquita. O trabalho das mulheres no sistema produtivo da várzea amazônica. In: SCOTT, Parry; CORDEIRO, Rosineide; MENEZES, Marilda (Org.). Gêenero e geração em contextos rurais. Santa Catarina: Mulheres, 2010. p. 233-252.

WANDERLEY, Maria de Nazareth Baudel. Raízes históricas do campesinato brasileiro. In: TEDESCO, João Carlos. Agricultura familiar: realidades e perspectivas. Passo Fundo: EDIUPF, 1999. p. 21-55.

WANDERLEY, Maria de Nazaré Baudel. Jovens rurais de pequenos municípios de Pernambuco: que sonhos para o futuro. In: CARNEIRO, Maria José; CASTRO, Elisa Guaraná de (Org.). Juventude Rural em perspectiva. Rio de Janeiro: Mauad X, 2007. p. 35-51.

WANDERLEY, Maria de Nazareth Baudel. Juventude rural: vida no campo e projetos para o futuro. Recife: UFPE, 2013. 270 p.

WEISHEIMER, Nilson. Juventudes rurais: mapa de estudos recentes. Brasília, DF: Ministério do Desenvolvimento Agrário, 2005. 76 p. (Estudos Nead, 7).

WEISHEIMER, Nilson. Socialização e projetos de jovens agricultores familiares. In: CARNEIRO, Maria José; CASTRO, Elisa Guaraná. Juventude rural em perspectiva. Rio de Janeiro: Mauad X, 2007. p. 237-252.

WOORTMANN, Klaas. Migração, família e campesinato. Revista Brasileira de Estudos de População, Brasília, DF, v. 7, n. 1, p. 35-53, jan./jun.1990. 